\title{
ЭВФЕМИЗМЫ И ДИСФЕМИЗМЫ: ЛИНГВОПРАГМАТИЧЕСКИЕ ОСОБЕННОСТИ В ПОЛИТИЧЕСКОМ ДИСКУРСЕ
}

\section{EUPHEMISMS AND DYSFEMISMS: LINGUISTIC AND PRAGMATIC FEATURES IN POLITICAL DISCOURSE}

\section{Tsaturyan}

Summary: The article discusses the features of euphemization and dysfemization in political discourse. It is noted that euphemisms used in political texts do not lose the euphemism status even if they are poorly connected with the denotatum, since they correspond to the basic parameters of euphemism identification (replace unwanted words or expressions, have a neutral connotation, help to avoid a communicative conflict). Dysphemisms, being in opposition relations with euphemisms according to the connective characteristic, are a means of undermining the general rules of communicative comfort.

Keywords: political discourse, euphemization, dysfemization, means of manipulation. $\ni$ вфемизм и дисфемизм - это два схожих процесса с противоречивыми эффектами, имеющие одинаковую базу и ресурсы, но разные цели [6]. Как эвфемизмы, так и дисфемизмы объединяются до такой степени, что иногда эвфемистические формы встречаются с уничижительным значением и, наоборот, дисфемистические формы могут иметь эвфемистическую функцию. Все зависит от коммуникативного намерения со стороны говорящего.

Согласно П. Брауну и С. Левинсону [4], вежливость считается мощным мотивом использования эвфемизма. Он играет большую роль в изучении того, как люди поддерживают отношения между ними с точки зрения взаимодействия и предотвращения угрозы их лицам. Р. Лакофф [6, с. 180] утверждал, что «вежливость обычно заменяет собой: в разговоре считается более важным избегать обиды, чем добиваться ясности». Очевидно, что когда мы общаемся с людьми из разных культур и обществ, мы должны уважать их самооценку, прибегая к таким вежливым стратегиям, как эвфемизм.

Многие люди утверждают, что мы можем знать значение слова, ссылаясь на его противоположность. Теория вежливости, по-видимому, несовершенна без введения ее противоположного понятия «невежливость», где Д. Баусфилд [3] называл последнее «давно забытым бедным двоюродным братом вежливости». Концепция не так проста, как кажется, и не может быть легко объ-
Цатурян Мариам Ашотовна

Соискатель, преподаватель, Кубанский государственный университет, г. Краснодар

ts.m-smile@mail.ru

Аннотация: В статье рассматриваются особенности эвфемизации и дисфемизации в политическом дискурсе. Отмечается, что эвфемизмы, используемые в политических текстах, не теряют статуса эвфемизма даже при условии слабой связи с денотатом, поскольку соответствуют основным параметрам идентификации эвфемизма (заменяют нежелательные слова или выражения, обладают нейтральной коннотацией, помогают избежать коммуникативного конфликта). Дисфемизмы, находясь в оппозиционных отношениях с эвфемизмами по коннатационной характеристике, являются средством подрыва общих правил коммуникативного комфорта.

Ключевые слова: политический дискурс, эвфемизация, дисфемизация, средство манипуляции.

яснена без создания сильных противоречий. Дж. Калпепер, Д. Боусфилд и К. Уилсон [11, с. 257] определили невежливость как «коммуникативные стратегии, предназначенные для нападения на лицо, и тем самым вызывают конфликт и дисгармонию». Это было в основном сосредоточено на современных ученых по двум основным причинам. Во-первых, точное объяснение термина вежливость долго рассматривалось. Во-вторых, теория вежливости была сформулирована и разработана П. Брауном и С. Левинсоном [4] на основе концепции защиты имиджа и поддержания уважения, что является конечной целью вежливости.

Эвфемизм вторгся в политическую сферу с той же свирепостью, что и в других сферах жизни. Он определяется К. Уилсоном [10, с. 77] как «слова со значением или звуками, которые как-то считаются более приятными, ясными или более возвышенными и поэтому используются в качестве замены слов, которые кажутся неприятными, грубыми или безобразными по звуку или смыслу». В англоязычном политическом пространстве, как правило, используются более приятные слова, чтобы заменить неприятные слова, которые могут вызвать недовольство и спровоцировать конфликт. Тем не менее, цели, стоящие за применением этой стратегии, могут быть центральной точкой в этом уравнении; это может использоваться для его способности сохранять лицо или для нужд маскировки, чтобы достигнуть определенных личных интересов. Как утверждал Каллен Мерфи [7, с. 16], «эвфе- 
мизмы аналогичны лейкоцитам, поскольку их появление в дискурсе вполне может быть признаком легкой или серьезной патологии - но это также признак того, что естественный защитный механизм задействован».

Анализ текстов англоязычных и русскоязычных газет показывает, что эвфемизмы и дисфемизмы, используемые в политическом дискурсе в средствах массовой информации, выполняют функцию речевого воздействия на получателя информации. Подобные слова в англоязычном дискурсе имеют несомненную силу в изменении состояния дела и в перенаправлении идеологии людей. В современном обществе приемы манипулирования информацией используется во всех сферах коммуникации.

В широком смысле речевое воздействие - это осознанное влияние на поведение индивида или группы индивидов посредством коммуникации и взаимодействия и связанных с ними речевых средств. В узком смысле под речевым воздействием понимают использование особенностей устройства и функционирования различных речевых средств, и прежде всего естественного языка, с целью построения речевых сообщений, обладающих повышенной способностью воздействия на сознание и поведение адресата.

Исход коммуникации определяется хорошим владением специальными техниками речевого воздействия. Выбирая тот или иной эвфемизм или дисфемизм, создатель текста преследует определенную цель: использование данной лексической единицы как средства актуализации определенного (заданного, или иллокутивного) смысла, т.е. получения перлокутивного эффекта. При этом создатели сообщения называют событие или явление разными лексическими средствами и с различной коннотацией, и тем самым формируют мнение широкой читательской (зрительской) аудитории о политике. Например:

"But Tory MP and Brexiteer Sir Bernard Jenkin appeared to accused Mr Bercow of bias, saying it was 'remarkable' how often the Speaker 'pleased one lot and not the other'. - Но член парламента от партии тори и сторонник Брексита сэр Бернард Дженкин вдруг обвинил Беркоу в предвзятости и сказал, как «замечательно» то, что Спикер часто чем-то очень доволен, а другим нет [1].

В приведенном отрывке использованы эвфемизмы (accused Mr Bercow of bias, $и$ it was'remarkable' how often the Speaker 'pleased one lot and not the other'), смысл которых неясен читателю ВBC News. Однако контекст сообщения раскрывает некоторые особенности работы Парламента Великобритании, в котором важную роль играет спикер (на тот момент им был Беркоу), но при этом он должен соблюдать нейтралитет: не оказывать предпочтений. Однако в процессе обсуждения Брексита и голосования, мистер Беркоу продемонстрировал свою поддержку определенной партии, и это поведение вызвало реакцию у представителя консервативной партии сэра Бернарда Дженкина, который и обвинил Беркоу в этом.

Ср. также другой пример, описывающий Б. Джонсона B "BBC news":

"Wages might be rising now and unemployment is low. But it doesn't feel like that to many people, and the Tories quite understandably can't escape all the political blame.

There is also, of course, the not insubstantial matter of the prime minister's slipperiness.

We've heard time and again around the country that people - even some of those who like him - often don't trust him.

In the campaign, for example, he is refusing to admit that his Brexit deal does involve extra checks for Northern Ireland, even though he acknowledged that back in October.

And there is a very long list of past comments that he has made that have caused real offence and worry to lots of different groups.

He's a politician who appears to enjoy controversy, but for many voters, he is just too casual with serious issues and, importantly, far too casual with the truth." [2]. - Пер: Заработная плата может, и растет сейчас, а безработица снижается. Но многие люди в это не верят, а тори, вполне понятно, не смогут избежать обвинений в проводимой ими политике.

Существует также, конечно, немаловажный вопрос об изворотливости премьер-министра. Мы неоднократно слышали по всей стране, что люди - даже те, кто любит его - часто не доверяют ему. В нынешней кампании, например, он отказывается признавать, что в сделке по Брекситу есть дополнительный вопрос по Северной Ирландии, хотя он был в курсе этого еще в октябре.

Также существует длинный список его комментариев, оскорбительных и обидных для разных групп населения.

Он - политик, который, кажется, наслаждается противоречием, но для многих избирателей он просто легкомысленно относится к серьезным проблемам и, что важно, очень легкомысленно относится к правде.

В приведенном примере дисфемизмы выражены при помощи различных языковых средств, усиливающих речевое воздействие: лексических повторов (casual with 
serious issues and, far too casual with the truth), языковой игры, основанной на антитезе (rising - low; like - don't trust), иронии (slipperiness), идиом (time and again), избежания двойного отрицания (not insubstantial), антонимов (rise - low, like - don't trust) образных средств (эпитеты - offence and worry, controversy), неологизмов (understandably) и др.

Таким образом, следует отметить, что в политическом дискурсе процесс эвфемизации оказывается опасной манипулятивной стратегией вежливости, которая никогда не стоит особняком, а скорее связана с рядом прагматических теорий, которые помогают достичь своей цели во всех контекстах [9]. Независимо от всех двусмысленностей, которые он создает, его дипломатическая функция сделала его предпочтительным способом подходить к оскорбительным и неприемлемым темам. Принимая во внимание тот факт, что эвфемистические выражения могут обеспечить вежливость, сохранить лицо и защитить самооценку, они также могут скрывать правду об острых событиях, скрывая их от общественности. Эта обманная стратегия не только заинтриговывает публику, но и прибегает к ее пользователям, которые «обманывают себя, оправдывая свои действия, несмотря ни на что» [8]. Дисфемизмы, находясь в оппозиционных отношениях с эвфемизмами по коннатационной характеристике, являются средством подрыва общих правил коммуникативного комфорта.

Из-за вышеупомянутых аргументов мы все же приходим к выводу, что эвфемизация и дисфемизация, как манипулятивные стратегии, могут быть полезны и в политическом дискурсе, поскольку главная функция стратегии - это смягчение смысла и замена неприличных, грубых или невежливых обозначений.

\section{ЛИТЕРАТУРА}

1. BBC News. 2020. Mps'Vote On Brexit Deal Ruled Out By Speaker. URL: https://www.bbc.com/news/uk-politics-50128740 (дата 0бращения: 10.03.2020).

2. BBC News. 2020. Will The Parties Pull Off Their Experiments? URL: https://www.bbc.com/news/election-2019-50714083 (дата обращения 10.03.2020).

3. Bousfield D. Impoliteness in interaction. - Amsterdam: Benjamins, 2008. - C. 2.

4. Brown P., Levinson S. C., Levinson S. C. Politeness: Some universals in language usage. - Cambridge university press, 1987. - T. 4.

5. Casas Gómez M. The expressive creativity of euphemism and dysphemism //Lexis. Journal in English Lexicology. - 2012. - №. 7.

6. Lakoff R. The logic of politeness; or minding your ps and qs Papers from the 9th Regional Meeting of the Chicago Linguistic Society //Chicago: Chicago Linguistic Society. - 1973. - C. 289.

7. Murphy C. The E Word: Why euphemisms warrant a statistical index all their own //ATLANTIC-BOSTON-. - 1996. - T. 278. - C. 16.

8. Rawson H. Op. cit. C. 5.

9. Rawson H. Rawson's dictionary of euphemisms and other doubletalk: Being a compilation of linguistic fig leaves and verbal flourishes for artful users of the English language. - Crown Publishers, 1995. - C. 1.

10. Wilson K.G. The Columbia Guide to Standard American English. - Columbia University Press, 1996. - C. 178.

11. Culpeper J., Bousfield D., Wichmann A. Impoliteness revisited: with special reference to dynamic and prosodic aspects //Journal of pragmatics. - 2003. - T. 35. №. 10-11. - C. 1546 .

(‥ Цатурян Мариам Ашотовна (ts.m-smile@mail.ru)

Журнал «Современная наука: актуальные проблемы теории и практики» 